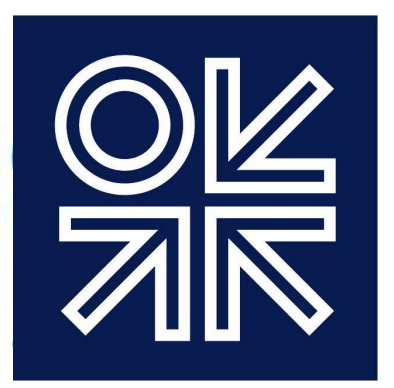

THE OXFORD

INSTITUTE

FOR ENERGY

STUDIES

February 2020

\title{
Energy systems thinking and the decarbonization of heat in the UK
}

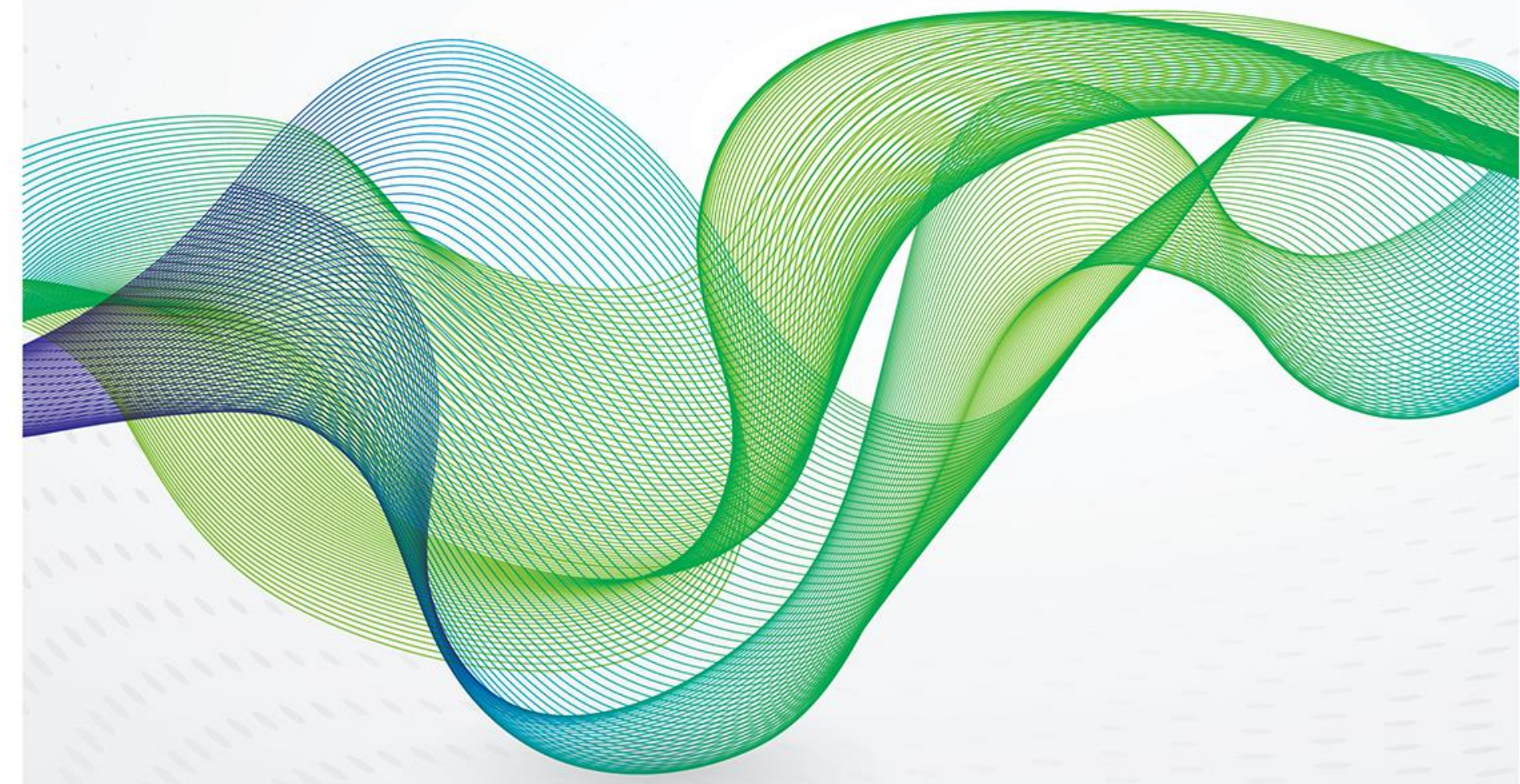


The contents of this paper are the author's sole responsibility. They do not necessarily represent the views of the Oxford Institute for Energy Studies or any of its members.

Copyright $\odot 2020$

Oxford Institute for Energy Studies

(Registered Charity, No. 286084)

This publication may be reproduced in part for educational or non-profit purposes without special permission from the copyright holder, provided acknowledgment of the source is made. No use of this publication may be made for resale or for any other commercial purpose whatsoever without prior permission in writing from the Oxford Institute for Energy Studies.

ISBN 978-1-78467-156-3

DOI: https://doi.org/10.26889/9781784671563 


\section{Contents}

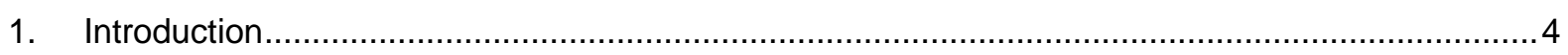

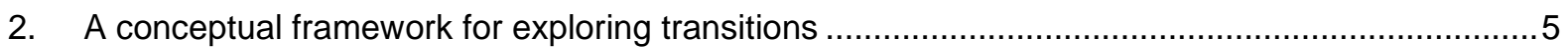

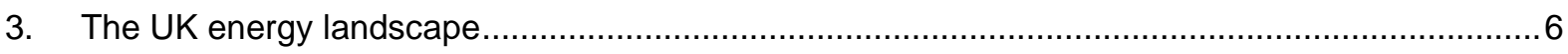

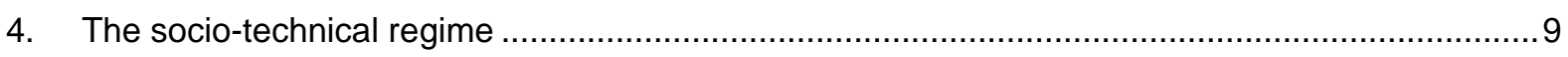

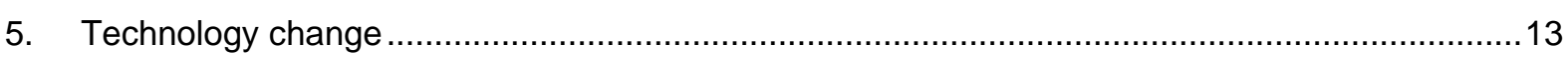

6. Decarbonization of heat in the United Kingdom ................................................................17

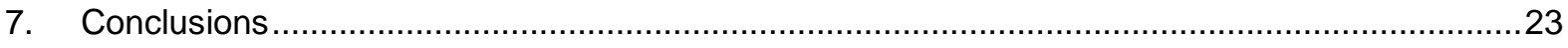

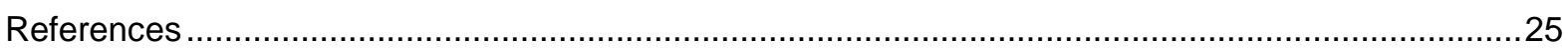

\section{Figures and Tables}

Figure 1: The multi-level perspective on technological transitions .................................................

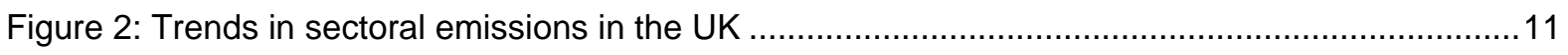

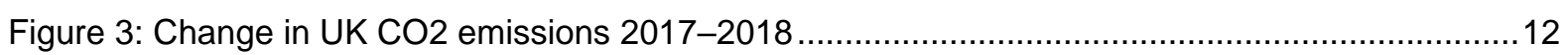

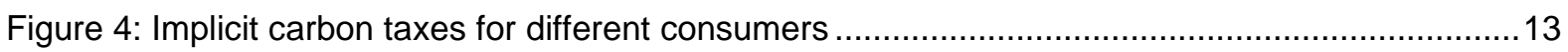

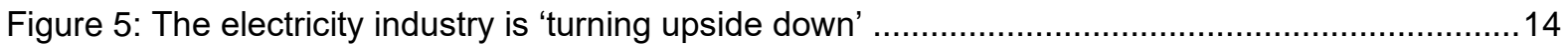

Figure 6: The path to heat decarbonization is less clear - how will demand for heat in 2050 be met?18

Figure 7: Probably a mix of solutions - though still leaves a big question Low-regret measures and

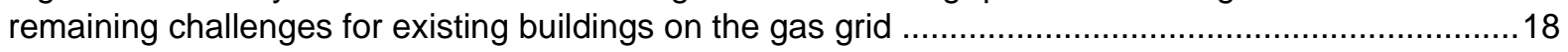

Figure 8: Hybrid heat pump solution currently favoured - boiler use across three winter weeks ........19

Figure 9: Implications across whole energy system: annualized system costs for alternative heat

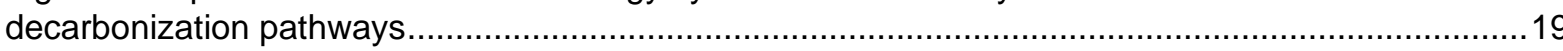

Figure 10: A systems approach also reduces costs - rapid uptake of electric vehicles and hybrid heat pumps could decrease the cost of electricity 


\section{Introduction}

This paper has two purposes:

1. To update the technical discussion in the author's earlier paper Decarbonisation of heat and the role of 'green gas' in the United Kingdom published in May 2018 (Keay 2018a). The critical development since then has been the UK Government's adoption of a zero net carbon target for 2050. This makes it unlikely that the central option examined in the 2018 paper replacement of natural gas by hydrogen produced by steam reformation of methane - will be an acceptable route to the decarbonization of heat. Even with carbon capture and storage (CCS), emissions would be too high for a zero-carbon scenario, as CCS normally removes only up to 90 per cent of the $\mathrm{CO} 2$ generated by the steam reformation process (though adding carbon dioxide use to the mix - making CCUS - could change the picture). However, the central problem discussed in the earlier paper remains - the peakiness of heat demand, which makes it difficult to rely on electricity alone. A hybrid option is therefore now the 'front-runner' in policy discussions, whereby the bulk of heat demand would be met by electricity via heat pumps, while peak demand only would be met by a hydrogen boiler. If efficiently operated, boiler use would be necessary for only about 10 per cent of the time, so any emissions could be kept to a very low level, making it realistic to assume that they could be offset by credits (if allowed) or negative emissions elsewhere in the economy.

2. To update and broaden the policy discussion in the earlier paper. That pointed to the challenges which a hydrogen-based solution would pose for policy makers - particularly in reconciling the need for a coordinated approach with a commitment to a liberalized market. But the policy questions have now taken on a new dimension. The hybrid approach suggested would have benefits not only in reducing emissions from heat, but also in creating a huge new interruptible source of electricity demand. Indeed, a recent study for the UK Climate Change Committee on Accelerated Electrification and the GB Energy System showed that an integrated approach across the whole energy system could actually reduce the price of electricity:

'While rapid deployment of electric vehicles and hybrid heat pumps and new renewable generation capacity will require new investments, together they could reduce the cost per kWh of electricity.' (CCC 2019b).

However, this implies an even larger coordination challenge than that of heat in isolation: the Government would have to take a systems approach to policy across the whole energy sector and this paper explores some of the difficult issues that such an approach would raise.

The paper is concerned with practical policy analysis rather than theoretical discussion. However, for convenience it uses a framework derived from 'transitions' theory, which looks at how major transitions in technologies and practices, such as that involved in the decarbonization of the UK energy system, can be realized. A commonly used approach here is the multi-level perspective developed by Dutch researchers Frank Geels and colleagues, and applied to the UK energy system by Shackley and Green (Shackley and Green 2007). This takes three levels of analysis: the first is that of the landscape (highlevel cultural and political values and trends); the second is the socio-technical regime of UK energy (in this case) itself; the third is that of emerging new technologies. The second of these levels is usually stable and involves a high degree of 'lock in' to existing technologies, policies, and practices. Transitions normally arise because of pressure and interaction with one of the other levels.

This paper briefly describes the conceptual framework (Section 1) before going on to look at the three levels described above (Sections 2-4). In the light of that analysis, Section 5 considers the specific case of the decarbonization of heat in the UK and some policy options. The paper concludes that the challenge is both unusual and unusually difficult for two reasons:

1. pressure is coming both from 'below', as it were, via developments in renewables and information technologies and from 'above' via the commitment to a zero net carbon target; 
2. in the view of this author some features of the 'landscape', and in particular of UK policy making, are essentially dysfunctional - what the author has described as a state of 'ideological limbo' (Keay 2016b).

\title{
2. A conceptual framework for exploring transitions
}

As explained above, this paper starts from the framework set out in Shackley and Green 2007. The authors note that:

\begin{abstract}
'the challenge of decarbonization involves no less than a transition from one set of technologies, practices, habits, regulations, values and perceptions to an alternative, low-carbon set of inter-related technologies and practise which fulfil the same or equivalent functions'.
\end{abstract}

This not only indicates the scale of the decarbonization challenge but actually understates it - at the time of writing the authors were envisaging a 60 per cent reduction target for greenhouse gas emissions, rather than the 100 per cent target now in place.

The framework adopted by Shackley and Green draws on the multi-level perspective developed by Frank Geels from his examination of transitions in other areas and is outlined in Figure 1.

Figure 1: The multi-level perspective on technological transitions

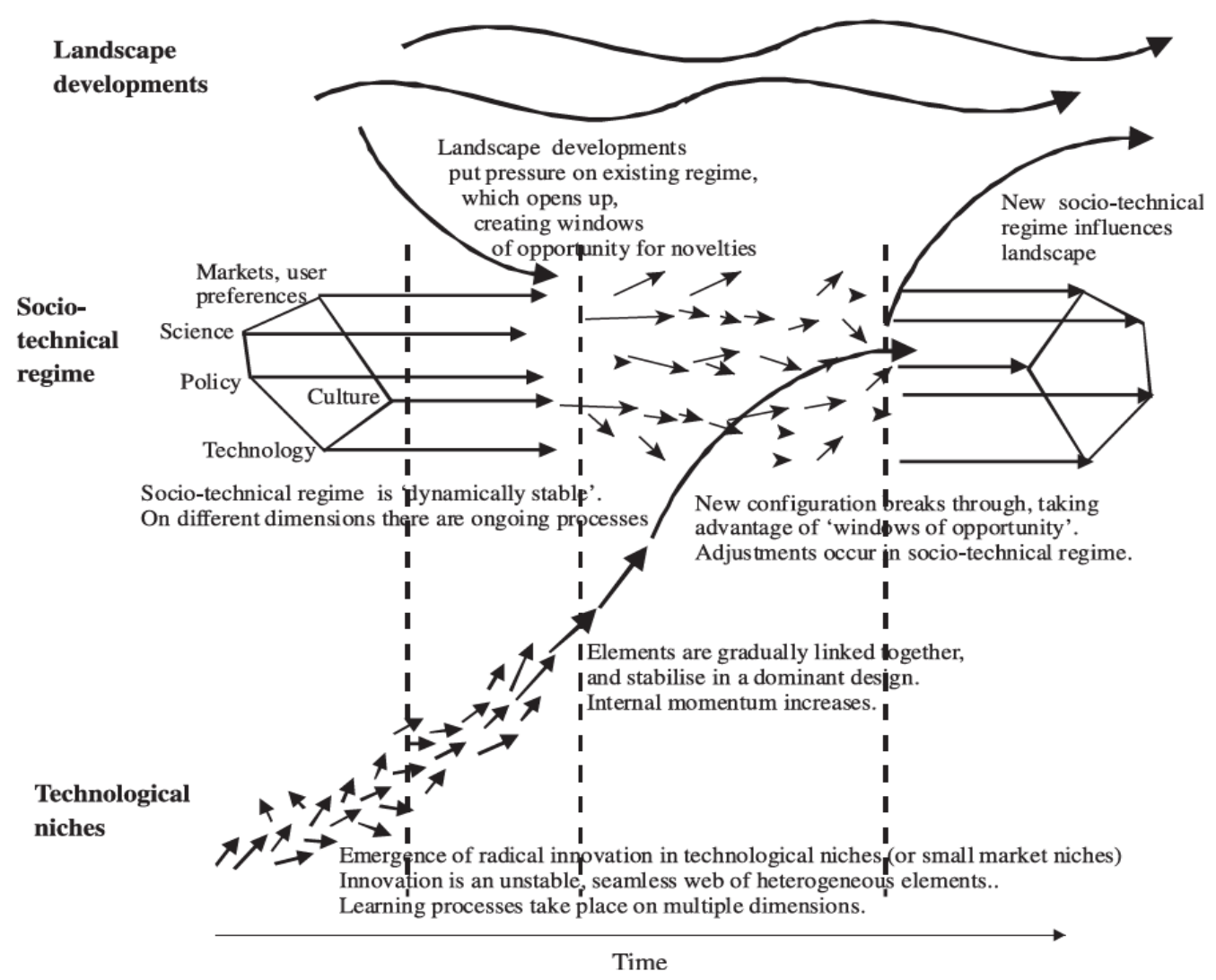

Source: Geels and Schot 2005

The energy 'landscape' above includes the dominant assumptions and values present at any given moment in time, along with deeply seated economic trends. This affects both the perception of problems and the preferred methods for addressing those problems (the 'policy paradigm' - discussed in the following section). 
The 'socio-technical' energy regime consists of the technologies used and their social, political, and institutional context, including regulation, consumer behaviour, institutional practices, and so on. Shackley and Green note that:

'It is at this level that 'lock-in' may take place, whereby technological regimes emerge alongside institutional and social changes (due, amongst other things to increasing returns to the scale of adoption)'.

There is therefore an inherent inertia in the socio-technical regime - it is 'dynamically stable'. This area is discussed in Section 3.

The 'technological niches' level is where new technologies emerge and in some cases replace the existing dominant technologies. However, because of the inertia of the existing regime, and the many interlinkages between technologies, practices, and institutions which have co-evolved within it, this is often an extended task and may involve fundamental and difficult change. This aspect is discussed in Section 4.

In this conceptual model, transitions typically occur through the interaction of two or more of the levels. The various forms of transition are analysed by Geels into different types. However, as noted above, the present author believes that the current transition is largely sui generis and the paper does not try to fit the challenges into one of the identified transition types.

\section{The UK energy landscape}

The energy landscape of the UK was relatively stable for three decades or so after the Second World War. The overall picture was of steadily growing energy demand, in general rising in line with Gross Domestic Product, while oil and electricity demand grew a little faster. The main concern of policy makers was to keep up with this rising demand and maintain security of supply. Apart from oil, dominated by private companies, the sector was largely the sphere of publicly owned monopolies, at national and regional level, and there was at the time little appetite for changing the overall institutional structure. It seemed to have coped well with the one big change which had taken place over the period - the introduction of North Sea gas to replace the old 'town gas' produced on a municipal or regional basis from coal. The changeover was facilitated by increasing centralization of the gas industry via the Gas Council and then British Gas. The institutional structure, and the lack of competition, made it much easier to plan, coordinate, and deliver a national strategy for converting all consumer appliances to the new source. Keay 2018a noted that the equivalent future task - of converting appliances for hydrogen use - would now be very much more complex because of the introduction of a liberalized market.

So when the first great challenge to the post-War energy landscape appeared, in the form of the oil crises of the 1970s, Governments did not have to search hard in their policy armoury to find the tools to effect the transition they now believed to be needed - a shift out of oil. They could direct the monopoly industries, which they ultimately controlled, to deliver the results they wanted; this approach was set out in the words of the International Energy Agency's 'Principles for Energy Policy' as

'reducing in absolute terms or limiting future oil imports through conservation of energy, expansion of indigenous energy sources and oil substitution.' (Scott 1994).

Pricing was not central to these aims; indeed, Governments often distrusted markets. For instance, in 1982 the International Energy Agency (IEA)'s World Energy Outlook argued that:

'the current outlook for short-term stability in energy markets and the oil market in particular is deceptive because signals in today's surplus oil market do not reflect the underlying medium and long term trends. In fact, these trends point to recurrent oil supply stringency later in the 1980s and thus to the need for constant attention to energy policy as a means of avoiding severe economic constraints'. (IEA 1982)

In other words, Governments thought they knew the future better than markets and were prepared to act on this supposed knowledge, ill-founded though it turned out to be. In fact, the surplus market of 
1982 was a sign that markets were indeed responding to the oil shocks of the 1970 s and - far from tightening at the end of the 1980s as the IEA had expected - oil prices collapsed in 1986 and remained low for more than a decade thereafter.

This was not the only problem with the centralized approach. Wider socio-economic trends were at work and in the 1980s the policy landscape changed fundamentally. The Government adopted a policy of privatization and liberalization, introducing competition across the energy sector. Not only did it accept that this meant giving up some policy tools, it actually welcomed that development. It turned its back on energy planning and specific quantified policy objectives and saw the Government's role in different terms - as doing no more than setting the framework in which market forces could work on a level playing field to determine the most efficient result. As the then Secretary of State for Energy, Nigel Lawson, put it in a speech in 1982:

'I do not see the Government's task as being to try to plan the future shape of energy production and consumption .... rather to set a framework which will ensure that the market operates in the energy sector with a minimum of distortion.' (Lawson, 1982)

The problem with this approach is that it only works when circumstances are favourable and the outcomes which markets produce are acceptable to governments. This remained largely the case during the 1990s when, in Dieter Helm's words 'there was little or no energy policy to make'. (Helm, 2003, p 124)

This led to a mindset which has been described as 'market innocence' (Wicks 2009).

'Market innocence in this sense is the belief that you can have both free markets in energy and the specific outcomes which Governments prefer. This view was always bound to come up against the harsh test of reality at some stage.' (Keay, 2006 p 143)

Policy is now firmly back in the driving seat, with the commitment to a zero net carbon energy system by 2050 . Given the magnitude of this ambition, the very compressed timetable for action, and the inherent inertia of the socio-technical regime, as described above, it is clear that a major push, either from the policy level, or the technological level, will be needed to effect the transition - and it is not clear that either is equipped for this effort.

At the policy level, Governments remain in a state of what the author has called 'ideological limbo', still at one level committed to reliance on markets and market forces, yet forced to intervene regularly on an ad hoc basis to achieve particular objectives, thereby undermining the very market forces they profess to rely on. They have not looked at the energy system as a whole to identify the market-friendly instruments which could create the incentives they want across the whole sector and there may be a question of whether it is now too late to do so. Indeed, over 10 years ago, in the study referred to above, the present author wondered whether they had ever really made the attempt. In discussing the need to promote investment in low-carbon electricity, such as renewables, the author accepted that Governments had moved on from complete 'market innocence'. However, they had not really developed an accommodation between their high-level commitment to markets and their desire to promote specific outcomes. Even the more sophisticated version of 'market innocence' - that minimally interventionist instruments could be used to achieve specific outcomes, while preserving the dynamism and efficiency of markets - was always somewhat optimistic and, in the view of this author, barely tried.

\footnotetext{
' ... the opportunity was not taken, during the early days when "little or no" policy was needed, to develop the flexible instruments which would go with the grain of the market to deliver the desired results, so when policy came back into the frame, Governments were at a loss - and hence unsuccessful - on how to achieve their various conflicting objectives.' (Keay 2006, p 143).
}

In the absence of any fully market-friendly policy tool, Governments therefore introduced various measures designed to encourage investment in particular low-carbon technologies, particularly renewables and (in the UK) nuclear, via renewables obligations and feed-in tariffs (FiTs). These reduced the risk of investment in the chosen technologies and provided them with a secure revenue stream. There has since been further policy experimentation, and recently auctions have emerged as 
a favoured policy instrument for reconciling the wish for market forces and the desire for specific outcomes. But even this approach has its limits (explored in Keay and Robinson 2019); this is because, amongst other reasons, it is designed to promote specific centrally defined outcomes and does not take account of the 'systems' aspect which is at the centre of this study.

The policy problem should not be insoluble - there are in principle policy instruments which respect markets while providing the right incentives and many economists favour carbon pricing for this reason. In practice, however, neither the UK Government nor any other major economy has made carbon taxes the centrepiece of its decarbonization policy.

It is beyond the scope of this paper to examine the arguments in detail, but there are clear reasons for avoiding loading too much policy weight on taxes, among them that:

- $\quad$ Taxes at a level which would have made renewables economic, at least in the early 2000s, would have had to have been unacceptably high, in the hundreds of euros per tonne of carbon emitted (OECD, 2013; Schuman, 2014). In practice, the acceptable level of a carbon tax, whether in the European Union (EU) or even in the UK (which has unilaterally imposed a higher tax because of the low level of the price under the European Emissions Trading Scheme - ETS) has proved to be well below the level of effective support for renewables (>€100 per tonne).

- $\quad$ Experience with the ETS and the UK carbon floor price shows (Buchan and Keay, 2016) that it is almost impossible, politically, to make a strong enough commitment to a carbon tax especially a carbon tax on a rising trajectory - that would make it sufficiently credible well into the future, in order to underpin investment in long-term assets. High tax levels would have to be a stable feature of the policy landscape for an extended period to provide such credibility and there is not time, given the urgency of addressing climate issues, to wait for the perception of high carbon taxes to establish itself as a permanent feature of the policy landscape.

- A carbon price would be highly visible and therefore politically difficult. It would have potentially big distributional impacts, especially in the initial stages. In the early 2000s, at any rate, a tax applying to all fossil fuels would have led to a major increase in electricity prices, especially in countries relying heavily on coal. The cost of renewables support, by contrast, was hidden within overall electricity prices, had relatively low initial impacts, and rose in a gradual manner as supply from these sources grew (and even then there was strong political resistance in some countries).

- Taxes have a variety of functions and are subject to various different socio-political constraints, with the result that they do not normally reflect any single policy goal (see Section 3).

- $\quad$ There is also the problem of broken markets, which is discussed in Section 4 (Keay, 2016b). Markets were set up for the present socio-technical regime and do not match the characteristics of the incoming new technologies. Since they are based on short run marginal costs (srmc), an increasing penetration of renewables tends to lower wholesale electricity prices at times when they are generating (because they tend to be correlated), while carbon prices would normally come into play to a significant extent only at times when renewables are not all generating. Even a high carbon price might thus do little to promote renewables investment unless accompanied by significant market reforms.

Clearly there are, at least in principle, ways round these problems and there is scope for different approaches to carbon pricing which might have more popular support - for example by recycling revenues to addressing fuel poverty or encouraging energy efficiency (Klenert et al., 2018). Nonetheless, the fact remains that no Government has chosen to make carbon taxes the central element of its decarbonization policy. There are other market-friendly approaches to the problem and the author's own preferred approach is a tradable carbon intensity target (Buchan and Keay 2016 Annex 2; Energy Catapult 2019, SEA 2020); however, these have not even been tried on any significant scale in the UK. 
So, at the moment the policy landscape is, in the view of this author, dysfunctional. It has taken on clear and ambitious goals without developing policy instruments consistent with its 'policy paradigm' to deliver those goals.

\section{The socio-technical regime}

Although we tend to talk about energy as though it were a single homogeneous entity, in fact at present the UK has three more or less separate energy sectors:

Electricity: production is not at present dominated by a single input fuel, but it is changing in the ways discussed above. On the demand side electricity is mainly used (over 75 per cent) in applications where there is little competition, such as appliances, lighting, and static motors such as pumps.

Heating: is dominated by gas (which provides about 80 per cent of heating).

Transport: is more or less monopolized by oil (over 90 per cent).

This tripartite division is not just a matter of chance. The fuels each have qualities which make them well suited to the sector concerned. For people to change their energy source is not just a matter of changing from one energy supplier to another; it may mean a change in the package of different capabilities being supplied and therefore in their whole relationship with the service in question.

For instance, oil is readily storable in large or small quantities and is very 'dense' in energy terms, meaning that a lot of energy can be contained in a relatively small volume. The quantities and delivery rates typical in oil for individual use would be regarded as being of industrial scale for electricity - for instance, a typical petrol pump delivers energy at a rate of some $10 \mathrm{MW}$; a car engine typically has a power of $60 \mathrm{~kW}$ or more; a car fuel tank may store some $1,000 \mathrm{kWh} .{ }^{1}$ This is on a different order of magnitude from the normal domestic electricity supply, which is usually a matter of a few kW at most and involves negligible amounts of (battery) storage. For electricity to take over the transport market would mean huge changes not just in infrastructure and supply but also in the consumer experience. This does not mean that it cannot (or should not) happen; but it does mean that Government policy should not regard this as just a relatively straightforward matter of substituting one source for another - it will require a fully integrated approach to such matters as energy supply and pricing, fuel delivery infrastructure, vehicle standards, consumer education, and so on. The sector exhibits a high degree of 'lock-in' to oil.

Similarly, with heating: gas is not quite so easy to store as oil, making it less suitable for transport, but it is clean and convenient and flexible. In the short term, balancing the system is not so critical as with electricity - there is more 'give' via short-term and longer-term storage and greater scope for pressure variation within pipes (linepack). All this makes gas suitable for heating loads with their high peak demands - estimated at around $150 \mathrm{GW}$ or more in the UK, or at least two and one half times the electricity peak, and possibly much higher (DECC 2013, Eyre and Baruah 2015). As with transport, electricity can probably not simply substitute for gas by providing exactly the same service in the same way, which would require enormous and expensive investment in electricity generation capacity. It is likely that qualitatively different forms of delivery will be needed - like electric heat pumps, which tend to produce heat in a steady and efficient, but not very speedy, fashion. The provision of an acceptable level of heating at reasonable cost is likely to mean using heat pumps in combination with better levels of insulation and perhaps heat storage.

Meanwhile, electricity itself also exhibits a high degree of lock-in. Because it is far and away the most convenient source of energy for appliances and Information and Communication Technology (ICT) use and because, for most appliances, electricity forms only a minor part of the total cost of ownership and use, electricity faces little competition and users are not particularly price sensitive. 
All these factors mean that not only do the three sectors exhibit a high degree of technology 'lock-in' (the inherent inertia referred to above); there is also a high level of policy 'lock-in'. Governments have been able, in effect, to follow three different policy paths for the three sectors:

- $\quad$ For oil in transport, Governments have been able to use a sort of Ramsey taxation, with fuel taxes at the highest level politically acceptable. These taxes are not specifically designed as a carbon price - if they were, they would be equivalent to a tax of about £250 per tonne of $\mathrm{CO}_{2}$ - but they are an important part of overall Government revenue and embedded in consumer expectations; they are a normal part of the policy landscape. For instance, in buying a new vehicle, UK consumers can count on fuel taxes continuing at roughly the present level or more. The position can be contrasted with that in the USA - the Federal fuel tax there has not been increased since 1993 and Governments (at least those with environmental goals) have relied on vehicle standards rather than taxation to drive improved fuel economy. By comparison, the UK fuel tax has increased over 20 times since 1993. However, it is unlikely that it could be increased to a level which could lead, on its own, to a wholesale decarbonization of personal vehicle use. Technical and infrastructure 'lock-in' in transport inhibits consumers from changing vehicle type - they may suffer from 'range anxiety' or lack convenient means of home charging. It seems likely that the planned move to Electric Vehicles (EVs) will be delivered, not primarily by price, but by a combination of subsidies for EVs and for new electric infrastructure like charging points, and of regulation (DfT 2018). In October 2018, the Government announced that after 2040, sales of new petrol and diesel cars will be banned. While there is no fully detailed strategy for the sector, there is therefore at least a broad sense of direction.

- Heating (dominated by gas) is politically sensitive. Rather than taxing it, the Government effectively subsidizes it by imposing a lower rate of Value Added Tax on fuels used for heating. Governments have also intervened in pricing, particularly at politically sensitive moments; for instance, promoting first 'tariff simplification' and then a price cap on domestic fuels. (Keay and Robinson, 2017 Section 3.2). Standards have played a role (for instance in the switchover to condensing boilers) but there has been relatively little regulation of the sector since the Clean Air Acts of the 1950s and 1960s. However, that is due to change; in his Spring Statement of March 2019, the then Chancellor Philip Hammond announced a ban on fossil fuel heating systems in new homes from 2025 - a move which he said would not only help protect the environment but also deliver lower fuel bills. However, not only is this date conveniently far in the future, but it is also clear that there is no overall strategy for decarbonizing heating at present, as discussed in Section 5.

- $\quad$ Electricity policy has followed a third route. It has been the main focus of decarbonization policy to date (for reasons discussed in Keay 2018a and with the implications set out below). Electricity emissions have fallen by more than half since 1990, as shown in Figure 2. 
Figure 2: Trends in sectoral emissions in the UK

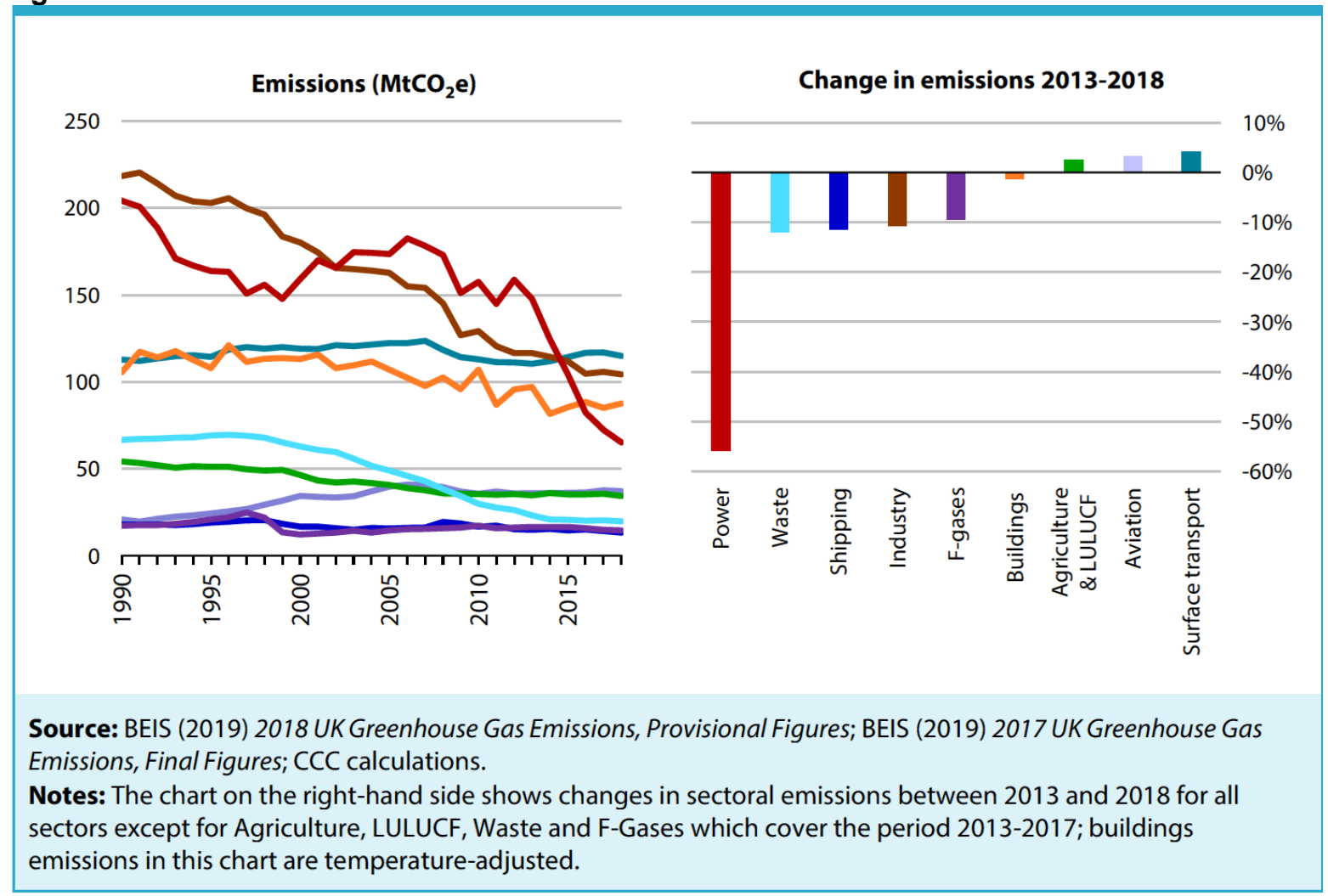

Source: CCC 2019c

The process continues (Figure 3). In 2017-18, electricity emissions fell by around 10 per cent and the UK Climate Change Committee (CCC) pointed out that:

'In 2018, for the fifth consecutive year, the sector with the largest percentage reduction in emissions was the power sector .... Excluding the power sector, economy-wide progress was much less positive, with emissions falling by 1 per cent on average .... Reaching net-zero emissions in 2050 will require an average annual emissions reduction of around $15 \mathrm{MtCO}_{2} \mathrm{e}$ (equivalent to 3 per cent of 2018 emissions)'. (CCC 2019c) 
Figure 3: Change in UK CO2 emissions 2017-2018

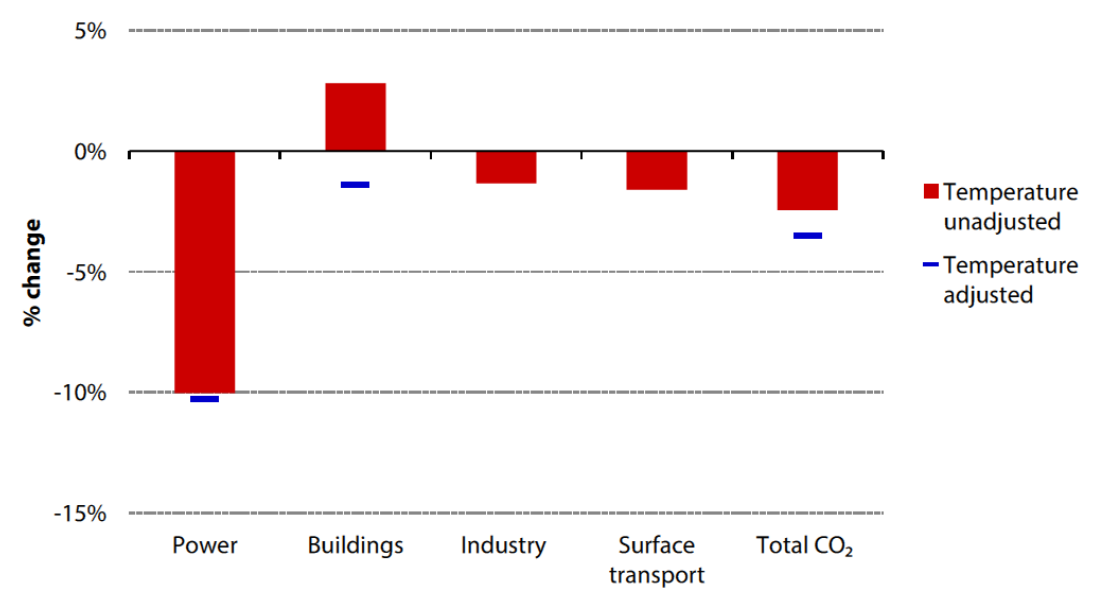

Source: BEIS (2018) 2017 UK Greenhouse Gas Emissions, Provisional Figures; BEIS (2018) 2016 UK Greenhouse Gas Emissions, Final Figures; CCC calculations.

Notes: $\mathrm{CO}_{2}$ emissions factors used for temperature-adjustment are based on energy use statistics, as published in BEIS Energy Trends. Emissions for Industry and Transport are not temperature adjusted. Total $\mathrm{CO}_{2}$ does not include emissions from international aviation and shipping.

\section{Source: CCC 2019c}

This focus on electricity for the achievement of carbon reduction has had profound implications for the electricity sector itself and for the growth of further anomalies across the energy sector more widely, first in the area of relative pricing.

The reductions in the electricity sector have been driven by a combination of measures: the Carbon Price Floor imposed by the UK Government to underpin signals from the EU ETS (albeit with special arrangements, such as free allocations for energy intensive users); Renewables Obligations Certificates, FiTs, and energy efficiency measures; and so on. The direct and indirect costs of these measures (such as extra transmission costs) have been incorporated in the consumer price in a manner which owes more to political constraints than to any consistent approach to carbon taxation. Figure 4 shows how the implicit carbon price paid varies by end-user and fuel type, and how it was foreseen as increasing over time for most users as the cost of the various support schemes has risen. It should be noted that the calculations are based on the situation as it appeared in 2013, when the report was written. One of the measures relevant to the comparison - the Carbon Price Floor applying to prices under the EU ETS - was, in 2013, expected to be on a steadily rising trajectory up till 2020. However, in 2014 the Government announced a freeze on the Price Floor from 2016. To that extent, the chart may overstate the growth in the discrepancies between different groups of consumers. But by the same token, it illustrates the point above - that it is difficult to make a future carbon price sufficiently credible to underpin investment. 
Figure 4: Implicit carbon taxes for different consumers

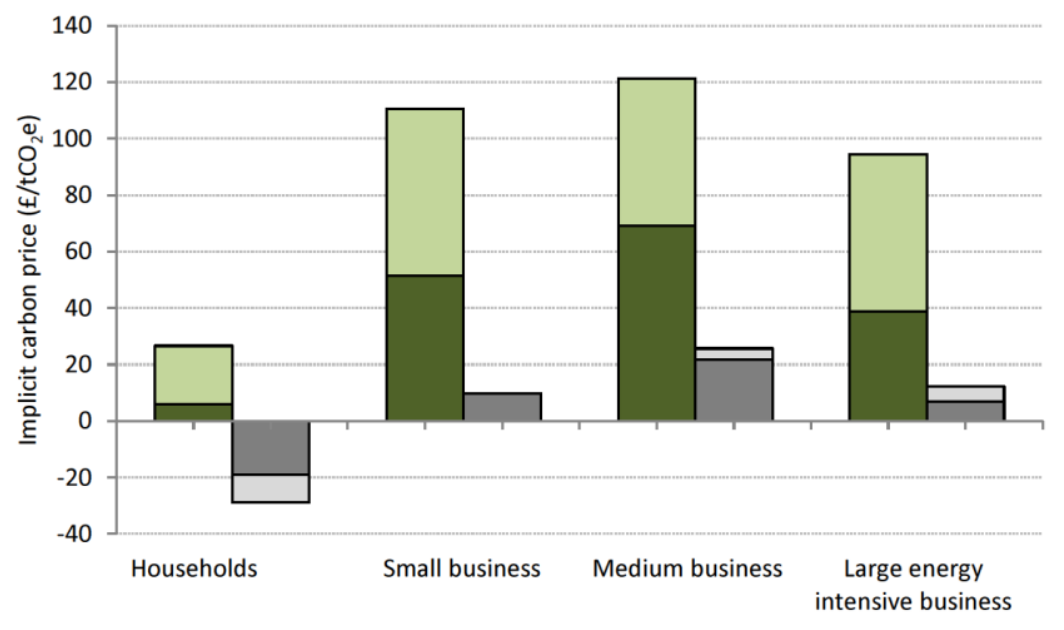

口Electricity 2013 aElectricity $2020 \quad \square$ Gas $2013 \quad \square$ Gas 2020

Source: IFS 2013

It also illustrates the fact that the anomalies have not been a matter of much concern to Governments, despite the fact that they make it more difficult to move on to the next stage of decarbonization if this is to involve the electrification of other sectors. In both heating and transport, electricity is becoming less competitive as a direct result of decarbonization to date.

The problem is that in the past Governments have not needed to treat energy as a single system; they have been able to deal with it as three separate sectors, each with their own constraints and opportunities, and they have got used to this approach to policy making. Policy approaches have differed hugely between the sectors without hitherto causing major distortions, given the limited interaction between them. But that will inevitably change in the future - experience with decarbonization of electricity, discussed below, already demonstrates some of the problems which come from failing to take a systems approach, while decarbonization of heat will throw up even greater challenges. Given the extent of policy and technology lock-in and the 'ideological limbo' of existing energy policy, it is difficult to foresee how successful Governments will be in achieving an integrated approach to the energy sector as a whole.

\section{Technology change}

As regards electricity, both of the forces for change noted in Geels' model have been at work in the UK: policy from above and technological change from below. The two processes have been largely mutually reinforcing - policy support for renewable sources has been one of the factors driving down renewables costs in recent years, and that fall in costs has made ambitious policy goals easier to achieve. But in fact, there have been two technological revolutions in electricity - not just in renewables costs but also in the rapid advances in ICT. Many previous assumptions about what was possible now seem outdated as a result of these developments. It is, for instance, now much easier to coordinate the operation of hundreds or thousands of separate distributed energy resources (whether in generation or demand response) and integrate them into an overall system.

But this is only one example of the way in which traditional thinking about the industry is changing and will have to change in the future. Another example is what the present author has called the 'broken markets' problem. The introduction of new renewables into the system is not just a question of replacing one set of resources by another; the new sources have a different set of economic and operating characteristics and affect the dynamics of the whole system. Market structures based on short run marginal costs are no longer effective in generating new investment, of providing meaningful signals to 
consumers, or in managing short-term operation. Governments have been struggling to fill the gap with measures like capacity markets to underpin reliability. But these in turn create new distortions and work to destabilize the existing regime, creating what Geels calls 'windows of opportunity'.

The changes have been so fundamental that nearly all the traditional assumptions about how the industry can and should operate have been overturned - in effect the industry is 'turning upside down', as outlined in Figure 5.

Figure 5: The electricity industry is 'turning upside down'

\begin{tabular}{|c|c|c|}
\hline & NOW & FUTURE \\
\hline Cost structure & Mainly marginal & Mainly capital \\
\hline Generation structure & Mainly centralised & Decentralised \\
\hline Pricing & kWh & $?$ \\
\hline Planning and operation & $\begin{array}{l}\text { Flex supply to match } \\
\text { demand }\end{array}$ & $\begin{array}{l}\text { Flex demand to match } \\
\text { supply }\end{array}$ \\
\hline Control and dispatch & From centre & $\begin{array}{l}\text { Throughout system (cf } \\
\text { internet) }\end{array}$ \\
\hline Role of demand-side & Passive & Interactive \\
\hline Role of grids & Neutral conduit & Smart player \\
\hline
\end{tabular}

Source: author

The contention of this author is that the industry is going through a transition from one socio-technical regime to another, whose outlines are only now emerging. This causes difficulties in policy making and the process been complicated by the fact that to date, because of the state of ideological limbo described above, Governments have not been able to come up with an overview of the whole transition. Instead, they have been elaborating responses to particular challenges more or less in isolation, hoping that they can then withdraw from intervention and let markets work as before - ignoring the possibility that markets will have to work very differently after the transition. To an extent, this piecemeal approach is understandable - many of the challenges are so new that Governments have little idea how to handle them in themselves, much less how exactly they could be integrated into an overall strategy. But the issue-by-issue approach entails risks; at some stage a more coherent framework will certainly be needed if the countries concerned are to avoid a significant misallocation of resources.

To take a simple example. In the future, because of the increasing penetration of intermittent generating sources, it will become ever more important to find the most efficient ways of meeting demand peaks. There are at least six or seven different options, all of which are likely to play a part, as discussed below. But to get the right balance between them, and optimize the system overall, there will need to be either efficient market signals or an optimized strategic framework. Neither exists at present.

The options for meeting peaks include the following:

- Central generation - the traditional route.

- Decentralized generation - as decentralized generation grows, it becomes ever more important to ensure that it is integrated into the system and that its potential role in system balancing is exploited to the maximum.

- $\quad$ Network reinforcement - this is likely to take on a significant role as distributed intermittent sources grow as a proportion of the total. Networks will need to be able to make optimum use of all the sources available at any one time and these will be widely distributed across the system.

- International interconnections - this is already a key means of balancing systems on a European basis; the UK has in the past suffered from its low level of interconnection, and the government has seen the need to expand interconnection capacity. 
- Demand response - growing in potential both because of supply side developments (more intermittent capacity) and increasingly smart systems on the demand side.

- $\quad$ Centralized and decentralized storage - technologies have been developing rapidly in recent years and costs have been coming down to near commercial levels. Both system-level and consumer-level storage are likely to be an important part of future systems.

- However, at present, each of these options is subject to a different system of regulation and each therefore faces different incentives. Nor have they been integrated into any overall strategy.

- Central generation - is mainly driven by market forces as far as operation is concerned. However, some systems, such as the UK, have also introduced capacity payments. There is no wider strategy underlying these capacity payments - the UK Government is not really clear about whether it wants specific sorts of capacity, or can accept market outcomes. Originally its aim was to promote the building of new Combined Cycle Gas Turbines (Keay 2016b but the main effect of the payments has been to encourage other sorts of capacity (including the retention of existing plants and the construction of small diesel peaking plants; neither outcome is really consistent with a low-carbon system).

- Decentralized generation - growth of decentralized plants has in the past been driven to a large extent by support schemes, such as the FiT payments, and a pricing structure which has had the effect of incentivizing embedded renewable generation. Recent changes have reduced the levels of support under these schemes and the pricing arrangements for electricity exported to the network were somewhat uncertain at the time of writing. But neither the past approach, nor the new uncertainty, has taken much account of overall system costs. FiTs were designed mainly to meet carbon targets and provide public benefits, not to optimize the system and minimize overall costs. Meanwhile, the regulator has argued that embedded generation has been over-rewarded; it is in the process of removing what it sees as a distortion and has the specific aim of keeping 'embedded benefits' that may distort investment or dispatch decisions under review (Ofgem 2019b). The move has proved controversial and it is not clear whether this sort of piecemeal development is going, on its own, to help create a level playing field, given the various other differences of approach noted in this section.

- $\quad$ Network reinforcement - is subject to regulation. The regulation is, to an extent, flexible but still gives a largely guaranteed return on investment (unlike, say, the returns for generation). There is also some encouragement for innovation but this is explicitly experimental. The regulator has made it clear that because of the uncertainties, it is not operating to any overall vision for the network of the future and that a number of significantly different scenarios are conceivable. (Ofgem 2009a).

- Interconnections - are also in practice usually subject to regulation, at least in the UK, but the regulation takes a different form from that for internal network reinforcement. It is mainly based around a 'cap and floor' approach, which helps underpin investment by reducing risk, and the regulator adopts a case-by-case approach to considering proposals (Ofgem 2018). While there is general acceptance that more interconnection is needed, there is no overall strategy. Furthermore, as with some other issues, this one requires an international approach for optimization.

- Demand response - a number of experiments are under way with different approaches (some linked with capacity mechanisms, some with network regulation) and there is no clear picture of how large a role demand response will play in the future system, or of what form it will take. Nor do current wholesale or retail prices give adequate incentives for demand response, and neither Government nor regulator has given a clear idea of how such price signals could be created (beyond hoping that the introduction of smart meters will enable greater resort to timeof-use pricing, which is unlikely to produce an optimum result if the 'broken markets' thesis is accepted). 


\begin{abstract}
Storage - this is only just starting to be recognized as a separate area by the regulatory system. Previously, its treatment was uncertain and potentially involved a sort of double counting, under which charges were made both for electricity imports and for electricity exports, as though storage was simply operating like a combination of generation and consumption; there was also some uncertainty about whether storage was a competitive activity (for generators) or could also be operated by network owners (distributors). Ofgem has been undertaking a consultation on the matter and in an open letter of 26 June 2019, it set out the steps it proposed to take to clarify the regulatory framework for storage, including a statutory consultation on changes to the electricity generation licence and a series of modifications to network charging. However, it rejected the view that a definition of storage was required in primary legislation and/or a separate licensing framework for storage, as a necessary precondition for equitable treatment and a removal of barriers to the deployment of storage (Ofgem 2019a). So, even at an overall systems level, it is not clear that storage has been fully integrated into the regulatory structure; and storage at customer level has received even less attention.
\end{abstract}

In short, although all six (or seven, if domestic storage is included) routes can be used to meet the same objective of mitigating the problems of intermittency, and while one key challenge for the future lowcarbon system will be to find the right balance between them, policy and incentives in each area are being developed separately and on different bases. There is no level playing field for competition, so market forces cannot be relied on to produce an optimum result. But there is also no central strategy national or European - or a 'system optimizer' who can make decisions based on an overall economic analysis of the optimum contribution from each source. The lack of any mechanism to ensure the right balance between different options could prove expensive - a report from the National Infrastructure Commission (NIC) in the United Kingdom estimated that getting the right mix could save £8 billion a year (NIC 2016).

There have been calls to develop a more coherent overall approach. For instance in his Cost of Energy Review (Helm 2017) Dieter Helm proposes rationalizing support for generation into a single system based on 'Equivalent Firm Power' auctions and for fundamental changes in the approach to network regulation. Helm argues that the existing system of periodic reviews has had its day. Technologies are moving so fast that it is almost impossible to forecast future cost savings - companies are therefore able to outperform against regulatory expectations, in effect making extra profits which could have benefited consumers. Furthermore, the traditional approach to network regulation, based on unbundling the industry into monopoly and competitive elements, is probably outdated. The distinctions between transmission, distribution, generation, and supply are being undermined. Different parts of the system are increasingly in competition with each other. For instance, a proposal for reinforcement or extension of the distribution network might in the past have been met by spending on the wires business; but now there are other options too, including local generation, storage, and demand-side resources. Helm argues that this means considering all the options together and, among other things, doing away with the distinction between different sorts of licence for generation, supply, and distribution.

He would also considerably downplay the role of Ofgem after the end of periodic reviews. Instead, he would establish new public system operators at national and regional level; these operators would determine what operations, maintenance, and enhancement to the networks were required and be responsible for ensuring their delivery, normally through competitive bidding.

While the present author has reservations about the specific Helm proposals (Keay 2018b), they do at least represent an attempt to move towards an integrated 'systems' approach, rather than relying on a series of piecemeal interventions. The Government's response to the Review was sympathetic overall, but they have not really taken on board its basic message and piecemeal intervention remains the order of the day. In other words, despite the clear benefits of a systems approach, as underlined by the NIC and the Helm Review, the Government has not in practice been able to make much of a move in that direction, even within the electricity sector seen in isolation. This raises big questions about the possibility of a wider systems approach, applying to energy as a whole - questions which the following section addresses. 


\section{Decarbonization of heat in the United Kingdom}

As discussed in Keay 2018a, the decarbonization of heat in the United Kingdom has been a more pressing issue than in many other countries, because of its rigorous, legally binding, climate regime. In 2018 the legal target was to reduce emissions by 80 per cent from the 1990 level by 2050 . That was a major challenge in itself. As noted above, emissions reductions to date have come mainly from the electricity generation sector, but to meet the 2050 target it was already clear that strategies for reducing emissions in other sectors, like heat and transport, would need to be developed quickly.

Since then the challenge has only become greater. A new goal has emerged, of reaching 'net zero' carbon emissions by 2050. This was driven by the objectives of the Paris Agreement of 2016, which aimed at:

'holding the increase in the global average temperature to well below $2^{\circ} \mathrm{C}$ above pre-industrial levels and to pursue efforts to limit the temperature increase to $1.5^{\circ} \mathrm{C}$ above pre-industrial levels, recognizing that this would significantly reduce the risks and impacts of climate change.'

In the light of this Agreement, in 2018 the Intergovernmental Panel on Climate Change produced a report entitled Global warming of $1.5^{\circ} \mathrm{C}$ (IPCC 2018). The IPCC discussed the objective of reaching and sustaining net zero global anthropogenic $\mathrm{CO}_{2}$ emissions (IPCC 2018, A.2.2) in order to meet the Paris target. The UK Government accordingly asked its official adviser, the Climate Change Committee, how soon it would be practical to meet the net zero goal. The Committee's report Net Zero - the UK's contribution to stopping global warning (CCC 2019a) was published in May 2019 and confirmed that the target could be met by 2050; the target was then adopted by the UK government in June 2019.

This increased the urgency of developing a strategy for heat. For instance, in 2016 the CCC had said that such a strategy needed to be developed by the first half of the 2020s (CCC 2016). In the light of the new target it stepped up the pressure, arguing that a Heat Roadmap was needed by 2020, and large-scale deployment of low-carbon heating systems must get under way before 2030 (CCC 2019b). The Government should also decide on the future of the gas network by the mid-2020s (CCC 2019c). The goal must be, by 2020, to:

'develop a fully-fledged strategy for heat. This must be designed to fully decarbonize buildings across the UK in line with the net zero goal.' (CCC 2019c).

Meanwhile, although the urgency is increasing, very little progress has been made - four out of five of the short-term targets proposed by the CCC have been missed (CCC 2019c).

But while the task is both more urgent and while little progress is being made, the challenge is also becoming more complex, because of the more ambitious target. As discussed in Keay 2018a, one of the main favoured solutions in 2018 was to introduce hydrogen for heating to replace natural gas currently far and away the largest single source. The cheapest way of generating hydrogen (and the main source worldwide today) is via the steam reforming of methane, discussed in the earlier paper. When combined with the use of CCS, this could in principle reduce emissions of $\mathrm{CO}_{2}$ to what were then seen as acceptable levels. (CCS only removes up to 90 per cent of the $\mathrm{CO}_{2}$ produced by the steam reforming process but, taken along with the fact that heating produces less than 20 per cent of UK emissions, this would be consistent with an overall 80 per cent reduction.) However, in a net zero carbon world, even a 90 per cent reduction is insufficient - especially when some other sectors (like industry and aviation) may prove even more difficult to decarbonize than heating and when the scope for 'negative emissions' via carbon use remains uncertain both in terms of the cost and of the quantities which could be removed in this way.

So, thinking has moved on to the consideration of alternative approaches. The overall strategy remains unclear and will depend on a wide range of factors, as shown in Figure 6. But this only accentuates the need to develop an overall strategy quickly. 
Figure 6: The path to heat decarbonization is less clear - how will demand for heat in $\mathbf{2 0 5 0}$ be met?

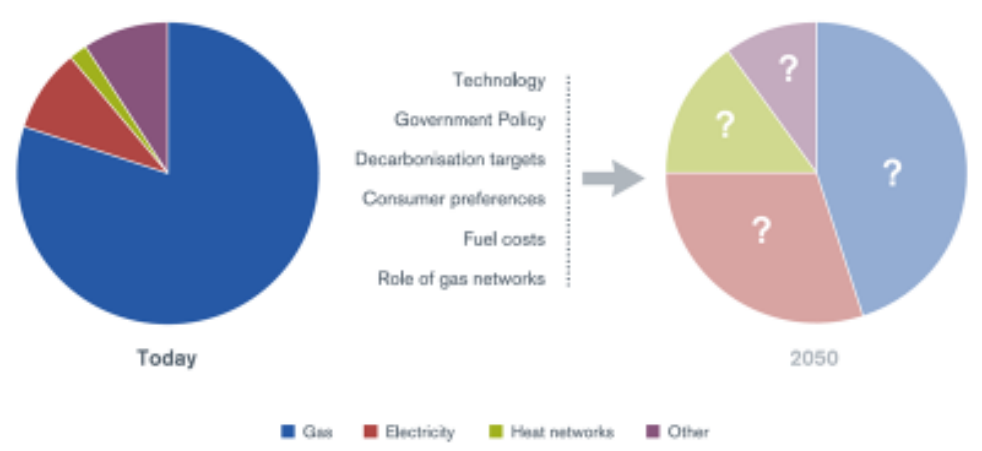

\section{Source Ofgem 2016}

What does seem clear is that a mix of solutions will be needed, with different approaches for buildings on the gas grid and for off-grid buildings, and a range of different measures including greater energy efficiency, low-carbon heat networks, and the use of heat pumps. But on most analyses, this still leaves a large residual gap to be filled - for properties on the gas grid but not on heat networks - as shown in stylized form in Figure 7:

Figure 7: Probably a mix of solutions - though still leaves a big question Low-regret measures and remaining challenges for existing buildings on the gas grid

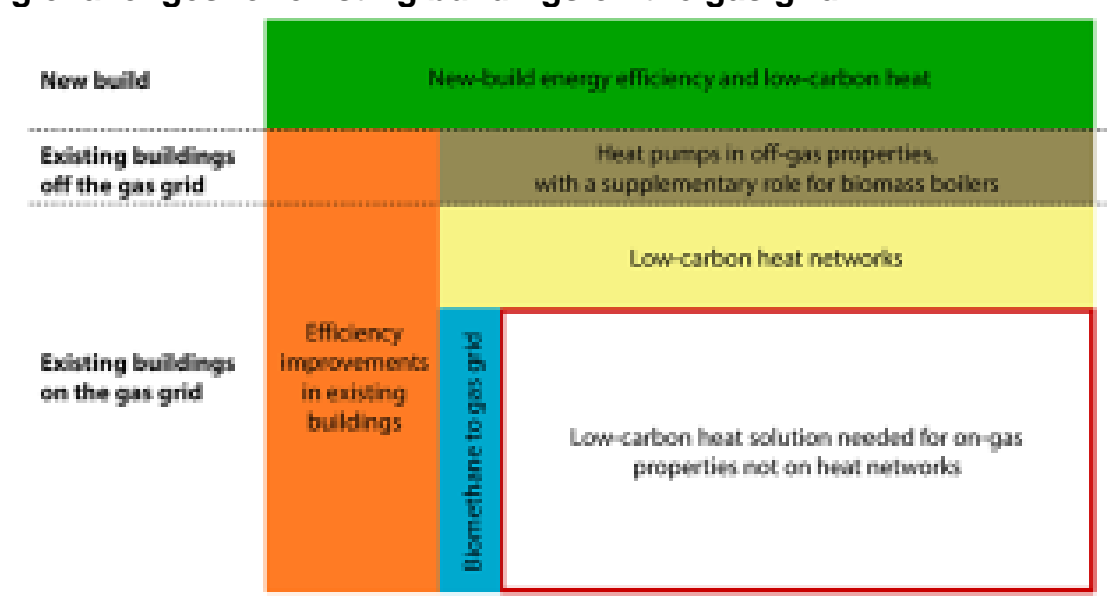

\section{Source CCC 2016}

Notes: The sizes of the blocks broadly reflect the scale of emissions reduction but not precisely. Some potential for heat networks will be in new-build and off the gas grid, rather than all on-grid as presented.

The underlying problem discussed in Keay 2018a remains however - that gas demand for heating is much more variable and much peakier than electricity demand. Various different estimates of the difference have been made, but the consensus is that peak heat demand is at least twice as high as current electricity demand. Meeting these peaks via electricity, even in the form of heat pumps, would be very expensive and require a huge increase in generating capacity (at a time when there are already significant problems in matching peak demand and generation because of the growth of intermittent generation capacity). Furthermore, heat pumps deliver heat at a slower and steadier rate than resistive heating boilers; either consumer behaviour would have to change in fundamental ways or Governments would have to intervene in consumer choice in a quite draconian manner (by banning electric resistive heating as well as fossil fuel heating) if the peak demand problem were to be met by an electricity-only route.

The solution currently favoured is therefore the so-called 'hybrid' heat pump model (CCC 2018, Imperial 2018, FES 2019). This would rely on heat pumps for the bulk of heat supply while peak heating demand 
would be met by an additional boost from a boiler (using hydrogen produced from the steam reforming of methane, or from electrolysis), along with a small amount of resistive heating. Figure 8 below shows the extent of boiler use across three winter weeks (in other words, when peak demand kicks in). Across the year as a whole, boiler use would be a much smaller portion of demand, probably only around 10 per cent if the system were run efficiently. This would enable any $\mathrm{CO}_{2}$ emissions to be minimized, to a level which could be coped with by offsets (if allowed) or negative emissions.

Figure 8: Hybrid heat pump solution currently favoured - boiler use across three winter weeks

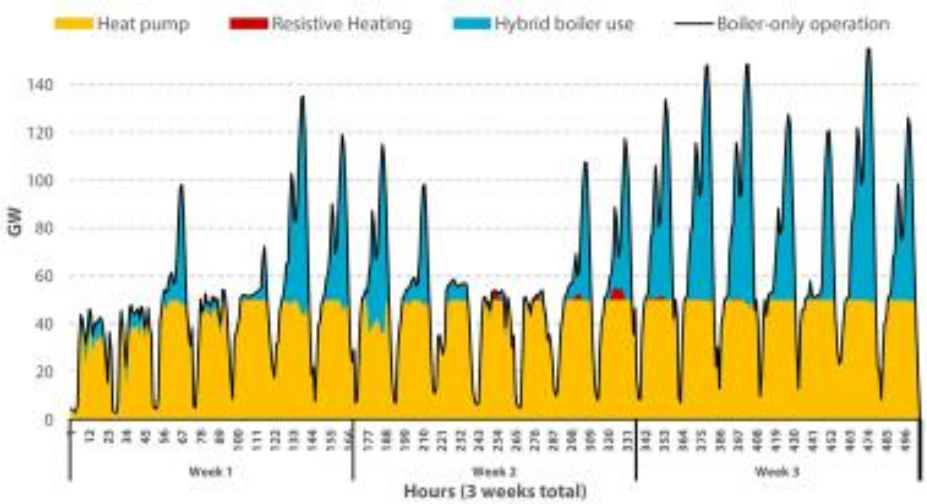

Source CCC 2018

The hybrid approach requires considerable investment, of course, but it could still be cheaper than an electricity-only solution, principally because the need for investment in electricity capacity would be lower, as shown in Figure 9.

Figure 9: Implications across whole energy system: annualized system costs for alternative heat decarbonization pathways

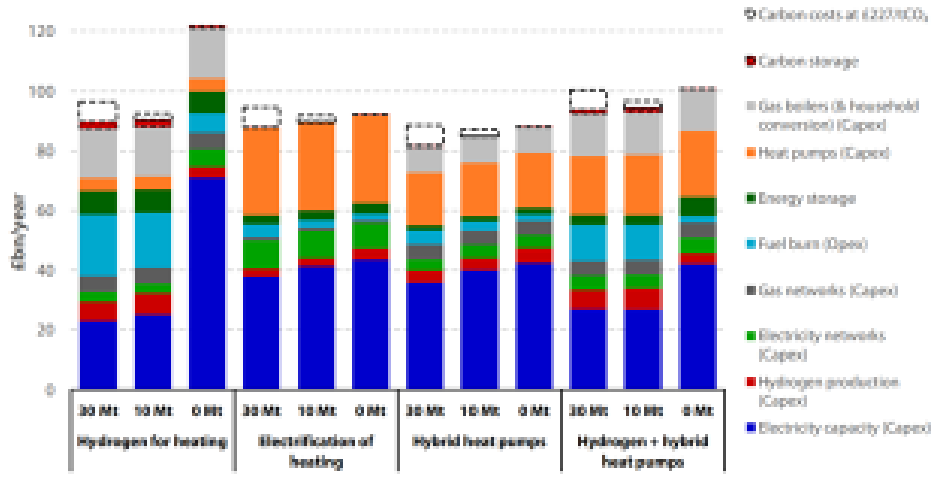

Source: CCC 2018; Imperial 2018, with follow up analysis by Imperial College

Notes: Chart shows total electricity and gas system costs, not costs compared to a counterfactual.

Furthermore, the hybrid approach to heating offers even greater benefits if the strategy evolves at an energy system level and is combined with a move to electric vehicles. In effect, it creates two major new areas of potentially flexible electricity demand - with appropriate pricing and other incentives, neither transport nor heating need add significantly to overall peak demand or increase electricity prices. Overall the systems approach should reduce overall costs, and could actually bring down the price of electricity, as shown in Figure 10: 


\title{
Figure 10: A systems approach also reduces costs - rapid uptake of electric vehicles and hybrid heat pumps could decrease the cost of electricity
}

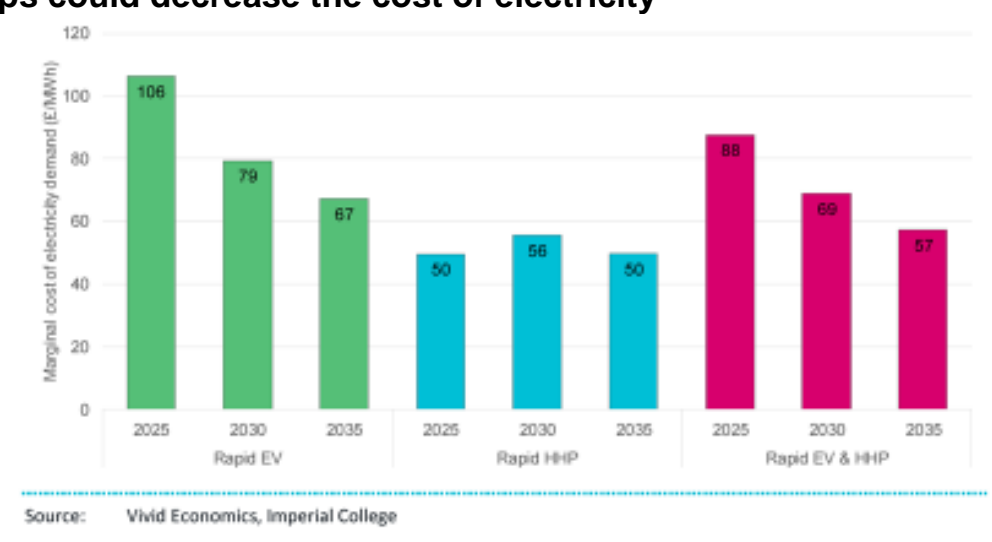

Source CCC 2019

But, despite the clear potential benefits of a systems approach to the decarbonization of heating, the obstacles to developing a coherent policy along these lines seem immense, among them:

- Uncertainty: In the power and transport sectors, the central need seems clear - to promote renewable sources in electricity and electric vehicles for transport. Even if a fully developed strategy may involve other elements (such as hydrogen), there is no pressing need to commit to these alternatives at this stage. Rapid progress can be made (as the power sector has shown) by a focus on these central elements, leaving the full strategy to emerge over time. With heating, the situation is different; as discussed above, many options are still potentially in play and for most or all of them the large-scale deployment needed would not only take considerable investment and disruption, but would need to be preceded by expensive pilot projects to assess the practicability of the favoured options. For a Government reluctant to 'pick winners' in a situation where there is no clear front runner, it is difficult to find a way through such a complex and expensive process.

- $\quad$ Price sensitivity: The heating sector is much more sensitive in political terms than transport and electricity, as noted above. Furthermore, and to a large extent because those sectors already have a significant fiscal and environmental burden incorporated in their prices, the price impacts of decarbonization on the heating sector could be politically unmanageable without significant social measures of one sort or another (subsidies and/or cross-subsidies) to ease through the process. For instance, the earlier paper on the decarbonization of heat noted that

\begin{abstract}
'For the consumer, there would be no advantage, and considerable costs, in a switch to hydrogen. These costs would involve adapting the consumer's own equipment plus the extra cost of the hydrogen itself arising from the efficiency losses involved in the steam reforming process; the cost of the reforming itself; the extra cost of CCS, and so on. It is difficult to estimate the full impact of these costs but as noted above, the calculations in H21 2016 suggest that delivered hydrogen could cost at least twice as much as today's natural gas supply. It is difficult to conceive of a politically viable tax which would more than double the cost of gas to consumers, as would be required to bridge the price difference between natural gas and hydrogen; furthermore, any tax would still be open to the objections above in terms of credibility, risk and so on'. (Keay 2018a)
\end{abstract}

- 'Lock-in' and consumers: The existing 'socio-technical regime' in heating displays a high degree of 'lock-in' - people are used to their gas boilers and there would have to be radical advantages in any alternative heating source to make them change. Even a price increase of the order discussed in the previous bullet point would probably not be enough to encourage a change - people would still have to change their burners, accept a new fuel they might perceive as dangerous, get used to different operational characteristics, and so on. None of the alternatives to natural gas has any clear benefits for consumers and all would involve higher 
costs, at any rate pre-tax. Again, the position is somewhat different from that of electricity and transport - with electricity, the penetration of renewables has taken place upstream and has not involved any change in behaviour by consumers; with transport, EVs have a number of consumer benefits and a clear public benefit in promoting clean air in cities.

- $\quad$ Network effects: In any event, it would be extremely difficult to present individual consumers with a direct choice between natural gas and hydrogen. The gas network can accommodate only a certain proportion of hydrogen without change, and there is no prospect of competing networks for hydrogen and methane in particular areas. Hydrogen, if it were the government's chosen option, would probably have to be introduced as a matter of central decision-making rather than consumer choice, and the process of changeover would need to be planned and centrally managed, with appropriate subsidies or cross-subsidies to ensure equity between different consumers. This sort of approach was feasible under the old centralized approach and worked fairly well in practice in the changeover to North Sea gas from town gas, but it would be very difficult for policy makers to develop an equivalent transition strategy on a competitive and market-led basis. The situation is in a way similar to that described in Keay 2006: during a period when there was no particular need to develop market-friendly policy instruments which could promote energy sector-wide decarbonization, Governments did not take advantage of the lack of urgency to explore the options. Now that such pioneering policy making is needed if Governments are not to have to resort to more direction of investment (as with electricity), they do not have the necessary tools available.

- Ideological obstacles: The result of the factors set out above is simply to increase uncertainty. Governments are not in a position to pick a technological winner, even if they wanted to do so; but promoting a consumer-driven outcome by the appropriate pricing of energy and the incorporation of environmental externalities is both politically unpalatable to the highest degree and unlikely in any event to produce the desired outcome, because of 'lock-in', network effects, and so on. As the apparent task, and the need for a more integrated systems approach, becomes more urgent and more complex, so the capacity of government for dealing with it declines.

- Coordination and the need to develop business models As discussed in Keay 2018a, one of the key problems in developing CCUS has been the need to coordinate the activities of the various different parties involved and create business models for each element in the picture. The problems are further compounded when, as described above, a systems approach is required which would coordinate the activities of different energy sources. The Government is certainly conscious of these issues and has published a consultation paper on possible business models (BEIS 2019). However, in some ways, that simply serves to underline the problems further. For instance, the paper gives as one objective to ensure that:

'hydrogen is deployed where it makes the greatest contribution to our decarbonization goals, rather than where it commands the highest market price'.

This seems to assume that market prices will always be out of line with emissions reduction goals (in other words, that the sort of pricing distortion noted earlier in this paper will be permanent). That both increases the likelihood that sub-optimal decisions will be made (given that there will be no valid market test) and increases the onus on Government to develop a fully informed understanding of the whole energy sector and of all relevant energy technologies (something which the current policy paradigm has not called for).

The likely outcome, at least from this author's perspective, is a period of policy stagnation, as the Government looks at a range of equally unattractive options for the heating sector and shrinks from deciding between them. In the short to medium term, this may not be critical in relation to the UK's climate targets - the difficulties in other sectors, and in particular transport and power, are considerable, but of a lower order of magnitude. However, as the CCC has emphasized, the longer-term consequences could be damaging. 


\section{Policy options}

Against this difficult background, it may be presumptuous for the author to try to suggest a way forward. However, even with a 2050 deadline, time is already short and urgent thinking about the options needs to take place. There may be no clear way forward, and no single option in policy terms, but the author suggests that a promising policy mix might be based around the following:

- A carbon intensity target The idea of a tradable carbon intensity target has been proposed in relation to electricity (Buchan and Keay 2016 Annex 2) and has also been discussed in relation to heat by a number of commentators (Energy Catapult 2019, Vivid Economics 2019, SEA 2020). A number of variants on the theme are possible, but it seems a promising avenue to explore in this context. It could provide clarity in terms of the objective, along with flexibility as to the means. Vivid Economics looks in particular at an obligation imposed on fuel suppliers and scores it relatively highly in its analysis. An alternative route, in order to encourage a systems approach rather than one based on individual fuels, would be to apply the obligation to heat providers (namely to the networks involved in distributing heat or the fuels used for heating). While this approach would create complications and could not be comprehensive (for example, it would leave out off-grid approaches, though these could be covered by a residual obligation on fuel providers) it could also provide greater flexibility of delivery (for instance, the gas grid could reduce the overall carbon intensity of the energy it provided by converting different parts of the country to 'green gas' at different rates). The conversion process would inevitably be lengthy and require considerable planning; an obligation, whatever form it takes, would need to provide the clarity and certainty to underpin a systems approach and long-term thinking, while at the same time providing enough flexibility to enable different approaches to be taken in different areas, as discussed in the next bullet.

- Local energy plans Different parts of the country might well require different approaches. There are big variations across the country in terms of housing stock, heating needs, and infrastructure and an integrated 'systems' view will need to be developed in each area with regard to these differences. Perhaps even more important will be ensuring that there is a degree of local consultation and 'buy-in' on whatever approach is eventually adopted in each area, and a uniform central approach is unlikely to be effective in achieving local acceptance. The existence of a local plan would not of course mean that the local public authorities would need to undertake delivery of the new heating approach - it is hoped that the carbon intensity standard suggested above would provide a framework within which companies can in most cases be the implementing organizations. But local authorities would need to be involved in facilitating the changeover and might in some cases take direct responsibility for doing so. One purpose of the plans could be to identify where such intervention is called for (within an overall national framework on the lines outlined below).

- 'Cluster'-based development Whether hydrogen is at the centre of the future zero carbon energy system is still uncertain. However, if hydrogen is likely to develop, a 'cluster'-based approach such as that advocated in ENA 2019 is likely to be needed. As described there, this would involve developing 'hydrogen clusters, initially based on anchor industrial (and transport) end-users and then into the buildings sector'. Even if hydrogen is not the main energy vector, some sort of 'bottom-up' development on these lines is likely to be needed. Yet (as discussed above and in more detail in Keay 2018a) it raises huge policy questions - can the 'clusters' be allowed to develop spontaneously or will the process need to be mandated and managed, and if so by whom? Can competition between suppliers be preserved as clusters develop? How can equity be maintained between different consumer groups (those within the 'clusters' will generally face higher costs, if not higher prices)?

- $\quad$ Attention to social needs The process will inevitably be both costly and disruptive. There will need to be a mechanism to ensure that the needs of vulnerable consumers are fully taken into account (and, in all probability, targeted help will need to be provided). 
Research, development, and demonstration support Many of the options to be explored are likely to need development or demonstration (for example, in relation to the safety of hydrogen) and some coordination will be needed at central level to ensure that this work is funded and carried out at an early stage, so that the results can feed into the development of the local plans.

- National policy framework Although it is suggested that the main emphasis should be on local energy plans, a national framework would also be needed to ensure coherence. A possible model lies in the approach taken under the Obama Administration in the USA towards the development of a Clean Power Plan. That is, the Plan could involve a centrally determined model for decarbonization; but also create flexibility at local level to adjust the model or even use a different approach, provided it can be demonstrated as being able to meet the same overall policy objectives and not create distortions. The approach would be further underpinned by providing that government grants - such as the Research, Development, and Demonstration support referred to above - would only go to qualifying projects and schemes certified as being consistent with the overall plan; and the threat of a centrally imposed plan if the local authorities fail to deliver.

- New institutional architecture It is likely that such an approach would require a new institutional framework to ensure delivery at local level - and possibly also at national level. The devolved administrations in Scotland, Wales, and Northern Ireland would be the natural bodies to develop plans for these nations; however, for England, while local plans would certainly need a large input from the existing local authorities, this would be a new area for these authorities and several would not be equipped for the oversight of such major exercises. It may be that new institutional structures would be needed to help carry them through. There is some discussion of possible institutional approaches in Keay and Robinson 2017. The general idea discussed there of a 'system architect' at national and local levels is one possibility worth pursuing further.

It will be apparent that every single one of these proposals would in itself mean a new policy direction of the sort the Government has little experience of or apparent appetite for - with the partial exception of attention to social needs and research and development (these, however, will both be problems some orders of magnitude greater than at present in relation to the energy transition). In combination, the proposals would lead to the need for a fundamental shift in the 'policy paradigm'. While a White Paper on Energy is, at the time of writing, expected (indeed overdue) and while the Government is due to produce a full net zero strategy in autumn 2020, there is little indication at present that the Government is yet prepared to face up to a challenge of this nature. Given all the uncertainties, it is perhaps understandable that it is reluctant to commit firmly to a radical change of course. However, the Government is running out of time: it does not have the leisure to indulge in continuous experimentation and a step-by-step approach.

\section{Conclusions}

Policy makers are facing a series of fundamental challenges in the goal of decarbonizing the energy system. Much analysis has shown that the cost of the transition could be minimized by taking a systems approach - an integrated strategy for the energy sector as a whole. However, this has not been the approach adopted to date. Although progress in decarbonizing electricity has been faster than in other areas, this has also thrown up a series of unintended consequences as the Government's piecemeal approach has failed to consider the implications of particular interventions for the electricity system as a whole. The Government is now facing an even greater challenge - the need to decarbonize other parts of the energy system - and the unintended consequences could be even more expensive and difficult to deal with. But they are not accustomed to taking a cross-sectoral approach; in the past it has not really been necessary, and it has been difficult to fit into their overall 'policy paradigm'. As a result, they have effectively adopted different policies for each major sector. However, it is clear that this continued piecemeal approach could be very expensive and could also significantly compromise their 
ability to achieve what is already likely to be one of the biggest policy tasks which a UK Government has ever had to face. At present the Government lacks both a clear 'policy paradigm' and the specific policy instruments which would be necessary to effect the transition efficiently. Given the many uncertainties, it seems unlikely that this situation will be clarified soon. The transition to a low-carbon energy system - like other major transitions in history - will involve not just changes in technologies, but also changes in practices, habits, regulations, perceptions, and values. These will have to happen at every level, including that of policy making. Some policy and institutional suggestions are proposed in this paper; they are radical and would inevitably require further discussion. However, in view of the urgency of the issue, the process of policy discussion cannot simply be put on the back burner while technical options are further explored. 


\section{References}

BEIS 2019 'Business Models for Carbon Capture, Usage and Storage', UK Department of Business, Energy and Industrial Strategy, July 2019.

Buchan and Keay 2016 Europe's Long Energy Journey: towards an energy union?, Buchan D. and Keay M., Oxford University Press, 2016.

CCC 2016 Next steps for UK heat policy, UK Committee on Climate Change, October 2016.

CCC 2018 Hydrogen in a low-carbon economy, UK Committee on Climate Change, November 2018.

CCC 2019a Net Zero - The UK's contribution to stopping global warming, UK Committee on Climate Change May 2019.

CCC 2019b Accelerated Electrification and the GB Energy System, Report for the UK Climate Change Committee by Vivid Economics and Imperial College, May 2019.

CCC 2019c Reducing UK Emissions - 2019 Progress Report to Parliament, UK Committee on Climate Change, London July 2019.

DECC 2013 The Future of Heating: Meeting the Challenge, UK Department of Energy and Climate Change, March 2013.

DfT 2018 The Road to Zero Next steps towards cleaner road transport and delivering our Industrial Strategy, UK Department for Transport London July 2018.

Energy Catapult 2019 Rethinking Decarbonisation Incentives: Future Carbon Policy for Clean Growth, Energy Systems Catapult Birmingham June 2019.

ENA 2019 Pathways to Net-Zero: Decarbonising the Gas Networks in Great Britain, Navigant (for Energy Networks Association), London October 2019.

Eyre and Baruah 2015 'Uncertainties in future energy demand in UK residential heating', Eyre, N. and Baruah P., Energy Policy 87 (2015) 641-53.

FES 2019 Future Energy Scenarios 2019, National Grid Energy System Operator, July 2019.

Geels and Schot 2005 Taxonomy of sociotechnical transition pathways, Geels F., Schot J., University of Eindhoven, 2005.

Helm 2003 Energy, the State and the Market - British Energy Policy since 1979 (revised edition), Helm, D., Oxford: Oxford University Press, 2003.

Helm 2017 Cost of Energy Review, Helm D., October 2017.

IEA 1982 World Energy Outlook, Paris: International Energy Agency, 1982.

IFS 2013 Energy use policies and carbon pricing in the UK, Advani A. et al., Institute for Fiscal Studies, London, November 2013.

Imperial 2018 Analysis of Alternative UK Heat Decarbonisation Pathways, Report for the UK Committee on Climate Change, Imperial College, London, August 2018.

IPCC 2018 Global Warming of $1.5^{\circ} \mathrm{C}$, Special Report by the Intergovernmental Panel on Climate Change, 2018.

Keay 2006 The Dynamics of Power, Keay M., Oxford: Institute for Energy Studies, 2006.

Keay 2016a 'Electricity Markets are broken - can they be fixed?', Keay M., OIES paper EL17, Oxford Institute for Energy Studies January 2016.

Keay 2016b 'UK energy policy - Stuck in ideological limbo?', Keay, M., Energy Policy vol 94 p 24752, July 2016. 
Keay 2018a 'Decarbonisation of heat and the role of 'green gas' in the United Kingdom', Keay, M., OIES paper EL29, Oxford Institute for Energy Studies, May 2018.

Keay 2018b 'Cost of Energy Review: Dieter Helm', Keay, Malcolm, Energy Policy, Elsevier, vol. 115(C), pages 216-20.

Keay and Robinson 2017 'Managing Electricity Decarbonisation: learning from experience - the cases of the UK and Spain', Keay, M. and Robinson, D., OIES paper EL23, Oxford Institute for Energy Studies April 2017.

Keay and Robinson 2019 'The Limits of Auctions: reflections on the role of central purchaser auctions for long-term commitments in electricity systems', Keay, M. and Robinson, D., OIES paper EL34, Oxford Institute for Energy Studies, April 2019.

Klenert et al. 2018 'Making Carbon Pricing Work for Citizens', Nature Climate Change, vol. 8 August 2018.

Lawson 1982 Nigel Lawson, Speech to International Association of Energy Economist, Churchill College, Cambridge, 28 June, reproduced in The Market for Energy eds Helm D., Kay, J., and Thompson, D., Oxford: Clarendon Press 1989.

NIC 2016 Smart Power, National Infrastructure Commission Report for UK Government, March 2016. OECD 2013 Effective Carbon Prices, OECD Paris, 2013.

Ofgem 2009 Long-Term Electricity Network Scenarios (LENS), Ofgem project update, March 2009.

Ofgem 2016 The Decarbonisation of Heat, Ofgem Future Insights Paper 2, November 2016.

Ofgem 2018 Cap and floor regime: Update on the Final Project Assessment stage for Window 1 interconnectors, Ofgem, October 2018.

Ofgem 2019a Clarifying the regulatory framework for electricity storage: Statutory consultation on proposed modifications to the electricity generation licence, Ofgem June 2019.

Ofgem 2019b Targeted Charging Review. For latest position at time of writing see https://www.ofgem.gov.uk/electricity/transmission-networks/charging/targeted-charging-reviewsignificant-code-review.

Schuman 2014 'The implicit carbon price of renewable energy incentives in Germany', Marcantonini, C. and Ellerman, D., Robert Schuman Centre paper 2014/28 European University Institute March 2014.

Scott 1994 The History of the International Energy Agency vol 2 Appendix 3, IEA Paris 1994.

SEA 2020 Achieving Net Zero: Regulating the Decarbonisation of Heat, Sustainable Energy Association, Birmingham, January 2020.

Shackley and Green 2007 'A conceptual framework for exploring transitions to decarbonised energy systems in the United Kingdom', Energy 32 (2007) 221-36.

Vivid Economics 2019 Greenhouse Gas Removal policy options - Final Report, Vivid Economics report for UK Department for Business, Energy and Industrial Strategy, June 2019.

Wicks 2009 Energy Security: a National Challenge in a Changing World, Wicks, M., Report for UK Department of Energy and Climate Change, August 2009. 